\title{
Optimal Performance of Caps' Pressing Process Using Taguchi-Grey Method
}

\author{
Abbas Al-Refaie ${ }^{1}$, Rami H. Fouad ${ }^{1} \&$ Nour Bata $^{1}$ \\ ${ }^{1}$ Department of Industrial Engineering, University of Jordan, Amman, 11942, Jordan \\ Correspondence: Rami H. Fouad, Department of Industrial Engineering, University of Jordan, Amman, 11942, \\ Jordan. E-mail: rhfouad@ju.edu.jo
}

Received: December 16, 2018

Accepted: December 26, 2018

Online Published: January 26, 2019

doi:10.5539/mas.v13n2p275

URL: https://doi.org/10.5539/mas.v13n2p275

\begin{abstract}
This paper aims at improving the performance of caps' pressing process using Taguchi-grey relational analysis. Five main quality characteristics were considered, involving cap's height, inner diameter, outer diameter, angle, and plastic weight. The individual and moving range control charts were constructed for each quality characteristic. Then, process capability analysis was then carried out to assess process performance at initial process factor settings, at which the process was found incapable in producing conforming caps for some quality characteristics. Thus, the Taguchi's designed experiments were employed to provide experimental layout followed by the grey relational analysis to determine the combination of optimal factor settings. Results showed significant in almost all the five quality responses and thereby resulted in huge production and quality cost savings.
\end{abstract}

Keywords: grey relational analysis, taguchi method, caps, control charts

\section{Introduction}

Because caps can withstand corrosive chemicals, plastic caps find extensive use for bottles used in packaging cosmetics, carbonated drinks, drugs, chemicals, and adhesives. The metal cap under study is depicted in Figure1. The caps' production line starts by cutting the rolls into sheet metals using big slitters. The metal sheet is covered with white licker (stick varnish). The production rate of this process is 5300 sheets per hour. The sheet metals are then turned over (white face) using a turnover machine to be ready for the next stage. Next, the printed sheets are moved to the pressing machine to form the caps, the pressing machine carries out twenty seven pressed crown caps. Caps are finally transferred to plastic injection and packaged. Five quality characteristics are of main importance to produce quality caps, including height, inner diameter, outer diameter, angle, and plastic weight, where nonconforming caps result in considerable manufacturing and quality losses. This research, therefore, aims at improving the performance of production process of bottle caps with five quality characteristics.

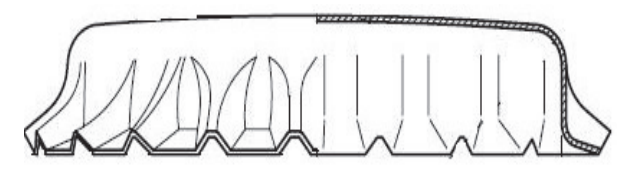

Figure 1. Crown cap diagram

The Taguchi method is widely applied because of its proven success in improving the quality of manufactured products for a single quality characteristic (Al-Refaie, 2014a,b,c). In reality, products are manufactured with multiple built in quality characteristics of main customer interest (Al-Refaie et al., 2009; Al-Refaie, 2012). Several optimization techniques were employed in previous studies to optimize process performance (Al-Refaie, 2015; AlRefaie et al., 2016; Al-Refaie, 2017). Among them, the grey relational analysis based on the grey system theory (Deng, 1982; Tsao, 2009) can be utilized for solving complicated interrelationships among multiple quality responses (Deng, 1989; Al-Refaie, 2010). This method has been employed to optimize performance in a wide range of business applications. For example, Jiang et al. (2002) applied machine vision-based grey relational theory to IC marking inspection. Lin et al. (2002) optimized the EDM process based on the orthogonal array with 
fuzzy logic and grey relation analysis method. Fung (2003) optimized manufacturing process for wear property of fiber-reinforced polybutylene terephthalate composites with grey relational analysis. Huang \& Liao (2003) optimized machining parameters of Wire-EDM bases on grey relation and statistical analysis. Tosun (2006). Determination of optimum parameters for multi-performance characteristics in drilling by using grey relational analysis. Nalbant et al. (2007) applied Taguchi method in the optimization of cutting parameters for surface roughness in turning. Pan et al. (2007) optimized multiple quality characteristics via Taguchi method-based grey analysis. Kuo et al. (2008) used grey relational analysis in solving multiple attribute decision-making problems. Somashekhar et al. (2011) conducted multi-objective optimization of micro wire electric discharge machining parameters using grey relational analysis with Taguchi method. Kacal \& Yıldırım (2013) applied grey relational analysis in high-speed machining of hardened AISI D6 steel.

This research, therefore, utilizes the grey relational analysis for optimizing the performance of the manufacturing process of bottle caps for multiple quality characteristics. The research results are valuable to process engineering by determining the combination of optimal process factors settings that result in quality as well productivity improvement. The remaining of this paper is outlined in the following sequence. Section 2 present the method. Section 3 implements the grey relational analysis for process improvement. Section 4 summarizes research results. Finally, Section 5 summarizes research conclusions.

\section{Method}

\subsection{Control Charts}

The control chart contains a center line $(C L)$, upper control limit $(U C L)$, and lower control limit $(L C L)$. Two rows of caps are produced by a single presser stroke; row A includes fourteen caps, while row B contains thirteen caps. Twenty samples; each of which contains two rows, are randomly selected then the five quality characteristics; height $(\mathrm{mm})$, inner diameter $(\mathrm{mm})$, outer diameter $(\mathrm{mm})$, angle (degrees), and plastic weight (grams), are measured on each cap as shown in Figure 2. The height of cap is measured using the Deal Gauge comparator. According to the specification the height shall fall between $5.93 \mathrm{~mm}$ and $6.07 \mathrm{~mm}$. The inner and outer diameters of the crown cap are measured using the Digital Vernier caliper. According to design, specifications of the inner diameter are limited between 26.7 and $26.9 \mathrm{~mm}$, while the outer diameters of cap are limited between 31.9 and $32.3 \mathrm{~mm}$. The angle of crown cap is limited between 12 and 18 degrees. Finally, the plastic weight is measured using the balance. The specification limits for the plastic weight is between 0.18 and 0.20 grams. The individual and moving range (I-MR) control charts are the constructed for each quality characteristic because of the repeated measurements on the samples differ due to laboratory or analysis error, and multiple measurements are taken at distinct locations on the same unit of product. For example, the I-MR control charts of cap's height for sample of rows A and B are shown in Figure 3. It is noticed that no point falls outside the $L C L$ and $U C L$ for both charts. In addition, no significant pattern or run is observed in these charts. Consequently, the process is concluded to be in statistical control for height. Similar conclusions are obtained from I-MR control charts of the inner diameter, outer diameter, angle, and plastic weight. 


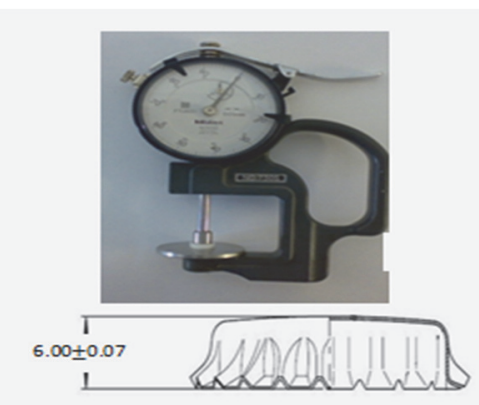

(a) Height $\left(v_{1}\right)$

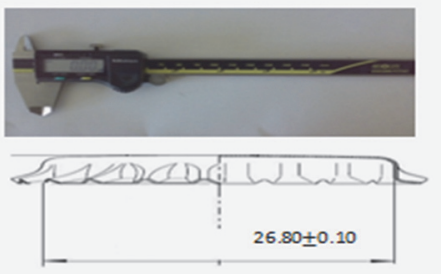

(b) Inner diameter $\left(v_{2}\right)$.

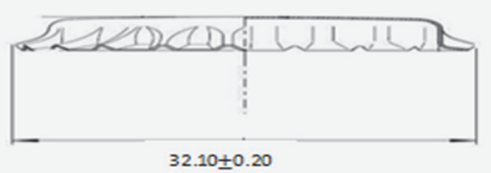

(c) Outer diameter $\left(v_{3}\right)$.
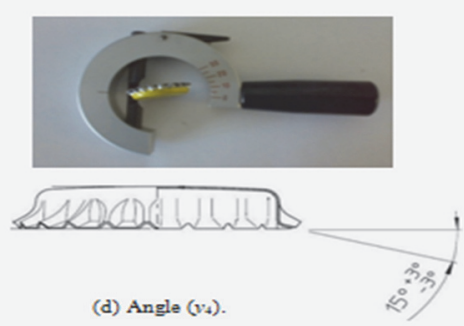

Figure 2. Measurement of cap's quality characteristics

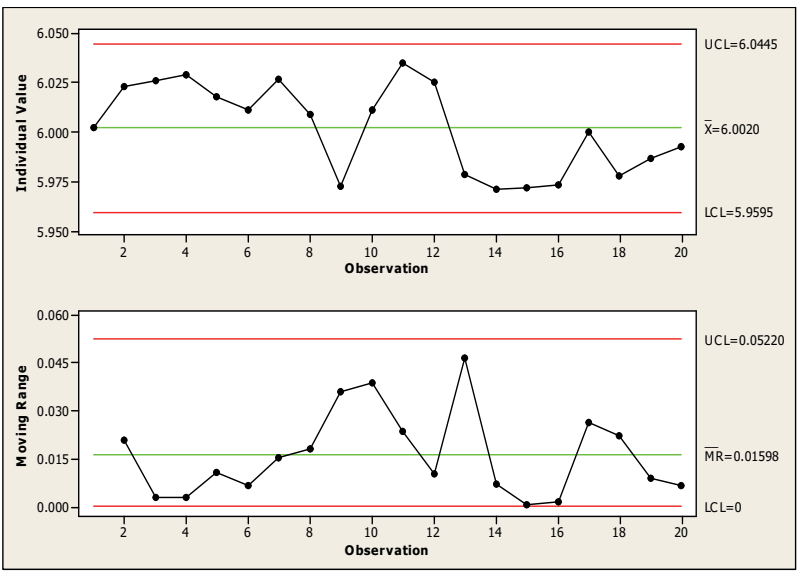

(a) Height (row A).
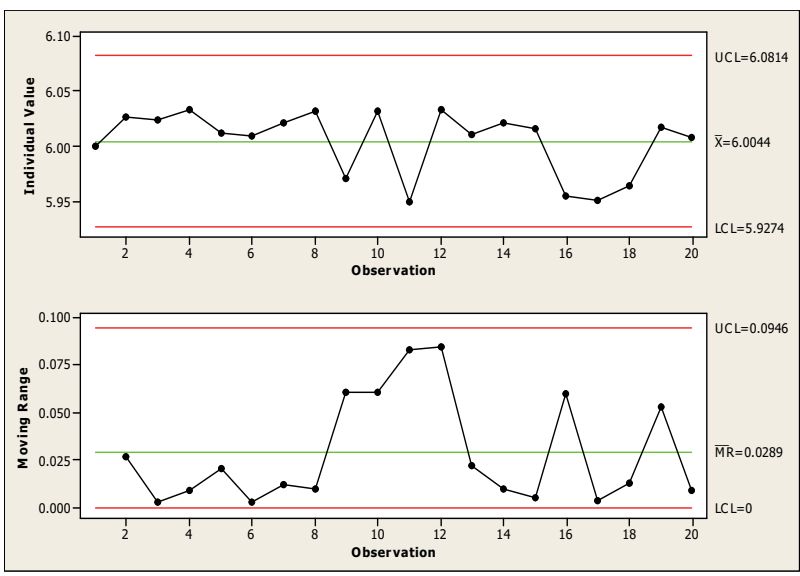

(b) Height (row B).

Figure 3. I-MR control charts for cap's height

\subsection{Process Capability Analysis}

Tables 1 and 2 display the quality characteristics' summary of control charts' parameters for row A and B, respectively. The process. capability analysis is an engineering study to estimate process capability. The estimated process capability ratio, ${ }^{C_{p}}$, first introduced as:

$$
\hat{C}_{p}=\frac{U S L-L S L}{6 \hat{\sigma}}
$$

where USL and LSL denote the upper and lower specification limits, respectively and $\hat{\sigma}$ is sample standard deviation for process. The process has both upper and lower specification limits. For one sided specifications, the one-sided capability index is defined as:

$$
\hat{C}_{p u}=\frac{U S L-\hat{\mu}}{3 \hat{\sigma}}
$$




$$
\hat{C}_{p l}=\frac{\hat{\mu}-L S L}{3 \hat{\sigma}}
$$

Process capability ratio for an off-centered process, $\hat{C}_{p k}$, is defined as:

$$
\text { 缷 }=\min \left\{C_{p l}, \mathcal{C}_{p u}\right\}
$$

The $\hat{C}_{p k}$ estimates the process capability when the estimated process mean, $\hat{\mu}$, is not centered between the specifications limits. To calculate the process capability ratio, the quality characteristic should be normally distributed. Tables 3 and 4 display the quality characteristics' summary of process capability indices for row A and $\mathrm{B}$, respectively.

Table 1. Summary of control charts calculations for row A.

\begin{tabular}{llllccc}
\hline \multirow{2}{*}{ Response } & \multicolumn{3}{c}{ Individual values } & \multicolumn{3}{c}{ Moving Range } \\
\cline { 2 - 7 } & $L C L$ & $C L$ & $U C L$ & $L C L$ & $C L$ & $U C L$ \\
$y_{1}$ : Height & 5.9595 & 6.0020 & 6.0445 & 0.00000 & 0.01598 & 0.05220 \\
$y_{2}$ : Inner Diameter & 26.7491 & 26.7916 & 26.8342 & 0.00000 & 0.01602 & 0.05233 \\
$y_{3}$ : Outer Diameter & 31.8836 & 31.9816 & 32.0796 & 0.00000 & 0.03680 & 0.12040 \\
$y_{4}$ : Angle & 14.8815 & 15.2241 & 15.5614 & 0.00000 & 0.12780 & 0.41760 \\
$y_{5}$ : Plastic Weight & 0.1941 & 0.1965 & 0.1989 & 0.00000 & 0.00090 & 0.00295 \\
\hline
\end{tabular}

Table 2. Summary of control charts calculations for row B.

\begin{tabular}{ccccccc}
\hline Quality & \multicolumn{3}{c}{ Individual values } & \multicolumn{3}{c}{ Moving Range } \\
\cline { 2 - 7 } Characteristic & $L C L$ & $C L$ & $U C L$ & $L C L$ & $C L$ & $U C L$ \\
$y_{1}$ & 5.9274 & 6.0044 & 6.0814 & 0.00000 & 0.02890 & 0.09460 \\
$y_{2}$ & 26.7557 & 26.7958 & 26.8358 & 0.00000 & 0.01506 & 0.04921 \\
$y_{3}$ & 31.9372 & 31.9717 & 32.0061 & 0.00000 & 0.01296 & 0.04233 \\
$y_{4}$ & 13.8220 & 15.0380 & 16.2550 & 0.00000 & 0.45700 & 1.49500 \\
$y_{5}$ & 0.1936 & 0.1963 & 0.1990 & 0.00000 & 0.00101 & 0.00331 \\
\hline
\end{tabular}

Table 3. Summary of process capability ratios for row A (Critical value $=1.6$ ).

\begin{tabular}{cccccccl}
\hline Response & $\hat{\mu}$ & $\hat{\sigma}$ & $C_{p}$ & $\mathrm{C}_{p l}$ & $\mathrm{C}_{p u}$ & $\mathrm{C}_{p k}$ & Decision \\
\hline$y_{1}$ & 6.0020 & 0.014167 & 1.647 & 1.694 & 1.600 & 1.600 & Critically Capable \\
$y_{2}$ & 26.7920 & 0.014202 & 2.347 & 2.159 & 2.535 & 2.159 & Capable \\
$y_{3}$ & 31.9820 & 0.032624 & 2.043 & 0.838 & 3.249 & 0.838 & Incapable \\
$y_{4}$ & 15.2210 & 0.113298 & 8.826 & 9.476 & 8.176 & 8.176 & Capable \\
$y_{5}$ & 0.1965 & 0.000798 & 4.177 & 6.876 & 1.479 & 1.479 & Incapable \\
\hline
\end{tabular}

Table 4. Summary of process capability ratios for row B (Critical value $=1.6)$.

\begin{tabular}{cccccccc}
\hline Response & $\hat{\mu}$ & $\hat{\sigma}$ & $C_{p}$ & $\mathrm{C}_{p l}$ & $\mathrm{C}_{p u}$ & $\mathrm{C}_{p k}$ & Decision \\
\hline$y_{1}$ & 6.0044 & 0.025621 & 0.911 & 0.880 & 0.968 & 0.853 & Incapable \\
$y_{2}$ & 26.7960 & 0.013351 & 2.497 & 1.520 & 2.397 & 2.397 & Capable \\
$y_{3}$ & 31.9720 & 0.011489 & 5.803 & 1.670 & 2.089 & 2.089 & Capable \\
$y_{4}$ & 15.0380 & 0.405142 & 2.468 & 2.120 & 2.500 & 2.437 & Capable
\end{tabular}




$\begin{array}{llllllll}y_{5} & 0.1963 & 0.000895 & 3.724 & 5.930 & 6.060 & 1.389 & \text { Incapable }\end{array}$

From Table 3 , it is noted that the process for row A is only found capable for $y_{2}$ and $y_{4}$. However, it is incapable for $y_{3}$ and $y_{5}$, critically capable for $y_{1}$. While in Table 4 for row $\mathrm{B}$, the process is judged capable for $y_{2}, y_{3}$, and $y_{4}$. But it is found incapable for $y_{1}$ and $y_{5}$. These results urge to conduct process improvement to enhance caps quality and save significant production and quality losses.

\section{Process Improvement}

A designed experiment is extremely helpful in discovering the key variables influencing the quality characteristics of interest in the process, it is also an approach to systematically varying the controllable input factors in the process and determining the effect these factors have on the output product parameters. Statistically designed experiments are invaluable in reducing the variability in the quality characteristics and in determining the levels of the controllable variables that optimize process performance. The main factors affecting the crown caps quality characteristics are temperature of the cooling system in the whole machine $\left(x_{1}\right)$, Machine production rate $\left(x_{2}\right)$, extruder speed $\left(x_{3}\right)$, and temperature of water to cool the punches $\left(x_{4}\right)$. Four factors each at three levels will be investigated for the crown caps, Taguchi's orthogonal array $\mathrm{L}_{18}\left(2^{1} \times 3^{7}\right)$ is utilized to conduct the designed experiments (Phadke, 1989; Taguchi, 1995). Current settings for the crown caps production machine are: Temperature of the cooling system at $3 \mathrm{C}^{\mathrm{o}}$, production rate of $2200 \mathrm{pc} / \mathrm{min}$, Extruder speed of $30 \mathrm{rpm}$, and Temperature of water of $3 \mathrm{C}^{\circ}$. The factor levels will be listed in Table 5 .

Table 5. Physical values of process factor levels.

\begin{tabular}{llll}
\hline \multirow{2}{*}{ Factor } & \multicolumn{3}{c}{ Level } \\
\cline { 2 - 4 }$x_{1}\left(\mathrm{C}^{\circ}\right)$ & 2 & 2 & 3 \\
$x_{2}(\mathrm{pc} / \mathrm{min})$ & 1900 & 3 & 4 \\
$x_{3}(\mathrm{rpm})$ & 25 & 30 & 2500 \\
$x_{4}\left(\mathrm{C}^{\circ}\right)$ & 2 & 3 & 4 \\
\hline
\end{tabular}

The experimental work was conducts utilizing the factor level combinations suggested in the $\mathrm{L}_{18}\left(2^{1} \times 3^{7}\right)$ array. The resulted response measurements are summarized in Table 6.

Table 6. The experimental results.

\begin{tabular}{|c|c|c|c|c|c|c|c|c|c|c|c|c|c|c|}
\hline \multirow{2}{*}{ Exp. $i$} & \multicolumn{4}{|c|}{ Factors } & \multicolumn{10}{|c|}{ Responses } \\
\hline & $x_{1}$ & $x_{2}$ & $x_{3}$ & $x_{4}$ & $y_{1 \mathrm{~A} i}$ & $y_{1 \mathrm{~B} i}$ & $y_{2 \mathrm{~A} i}$ & $y_{2 \mathrm{~B} i}$ & $y_{3 \mathrm{~A} i}$ & $y_{3 \mathrm{~B} i}$ & $y_{4 \mathrm{~A} i}$ & $y_{4 \mathrm{~B} i}$ & $y_{5 \mathrm{~A} i}$ & $y_{5 \mathrm{~B} i}$ \\
\hline 1 & 2 & 1900 & 25 & 2 & 6.010 & 6.006 & 26.804 & 26.792 & 31.999 & 32.010 & 15.429 & 14.692 & 0.224 & 0.214 \\
\hline 2 & 2 & 2200 & 30 & 3 & 6.011 & 6.004 & 26.803 & 26.804 & 31.966 & 31.995 & 15.071 & 15.308 & 0.217 & 0.219 \\
\hline 3 & 2 & 2500 & 35 & 4 & 6.002 & 6.000 & 26.791 & 26.802 & 31.974 & 32.008 & 15.071 & 15.615 & 0.252 & 0.255 \\
\hline 4 & 3 & 1900 & 25 & 3 & 6.023 & 6.027 & 26.761 & 26.768 & 31.938 & 32.002 & 15.429 & 15.077 & 0.226 & 0.220 \\
\hline 5 & 3 & 2200 & 30 & 4 & 6.009 & 6.018 & 26.800 & 26.802 & 31.973 & 32.032 & 15.786 & 15.154 & 0.215 & 0.215 \\
\hline$\vdots$ & $\vdots$ & $\vdots$ & $\vdots$ & $\vdots$ & $\vdots$ & $\vdots$ & $\vdots$ & $\vdots$ & $\vdots$ & $\vdots$ & $\vdots$ & $\vdots$ & $\vdots$ & $\vdots$ \\
\hline 15 & 3 & 2500 & 25 & 3 & 6.026 & 6.023 & 26.773 & 26.775 & 31.941 & 31.960 & 15.429 & 15.000 & 0.190 & 0.194 \\
\hline 16 & 4 & 1900 & 35 & 3 & 6.016 & 5.998 & 26.782 & 26.796 & 31.992 & 31.965 & 15.462 & 15.462 & 0.250 & 0.249 \\
\hline 17 & 4 & 2200 & 25 & 4 & 6.012 & 6.024 & 26.793 & 26.819 & 31.969 & 31.976 & 14.929 & 15.154 & 0.214 & 0.219 \\
\hline 18 & 4 & 2500 & 30 & 2 & 6.018 & 6.011 & 26.785 & 26.792 & 31.992 & 31.947 & 15.429 & 15.077 & 0.280 & 0.248 \\
\hline
\end{tabular}

The proposed procedure for optimizing the crown caps production process is outlined in the following steps:

Step 1: Calculate the signal-to-noise ( $\left.\mathrm{S} / \mathrm{N}, \eta_{i j}\right)$ ratio for each quality characteristic. Let $\eta_{i 1}, \eta_{i 2}, \eta_{i 3}, \eta_{i 4}$, and $\eta_{i 5}$ the 
$\mathrm{S} / \mathrm{N}$ ratio of the height, inner diameter, outer diameter, angle, and plastic weight at experiment $i$, respectively. The $\eta_{i j}$ values; $i=1, \ldots, 18 ; j=1, \ldots, 5$, are expressed using:

$$
\eta_{i j=10}\left[\log \frac{\bar{y}_{i}^{2}}{s_{i}^{2}}\right], \quad j=1,2,3 \ldots 5 ; i=1,2,3 \ldots 18
$$

where $\bar{y}_{i}^{2}$ and $s_{i}^{2}$ are the sample mean and variance, respectively at experiment $i$.

Step 2: It is necessary to normalize the $\mathrm{S} / \mathrm{N}$ ratio before using relational grey analysis. Normalize $\eta_{i j}$, to avoid the effect of adopting different units of the five quality characteristics.

$$
\eta_{i j}^{*}=\frac{\eta_{i j}-\min \left\{\eta_{i j}\right\}}{\max \left\{\eta_{i j}\right\}-\min \left\{\eta_{i j}\right\}} \quad j=1,2,3 \ldots 5 ; i=1,2,3 \ldots 18
$$

Table 7. Calculated $\eta_{i j}$ and $\eta_{i j}^{*}$ values.

\begin{tabular}{clllllllllll}
\hline Exp. $i$ & $\eta_{i 1}$ & $\eta_{i 2}$ & $\eta_{i 3}$ & $\eta_{i 4}$ & $\eta_{i 5}$ & $\eta^{*}{ }_{i 1}$ & $\eta^{*}{ }_{i 2}$ & $\eta^{*}{ }_{i 3}$ & $\eta^{*}{ }_{i 4}$ & $\eta^{*}{ }_{i 5}$ \\
\hline 1 & 66.54370 & 69.98870 & 72.28670 & 29.21770 & 29.81920 & 0.76700 & 0.23727 & 0.80032 & 0.00328 & 0.33033 \\
2 & 61.68220 & 91.57410 & 63.86000 & 39.14620 & 43.75880 & 0.57853 & 1.00000 & 0.37077 & 0.20930 & 0.77206 \\
3 & 72.55420 & 70.74400 & 62.48130 & 32.01650 & 41.54740 & 1.00000 & 0.26396 & 0.30049 & 0.06136 & 0.70199 \\
4 & 66.56820 & 74.65950 & 56.98160 & 35.74660 & 34.41340 & 0.76795 & 0.40232 & 0.02014 & 0.13876 & 0.47592 \\
5 & 59.50800 & 85.55270 & 57.69690 & 30.78580 & 35.57810 & 0.49425 & 0.78723 & 0.05660 & 0.03582 & 0.51283 \\
$\vdots$ & $\vdots$ & $\vdots$ & $\vdots$ & $\vdots$ & $\vdots$ & $\vdots$ & $\vdots$ & $\vdots$ & $\vdots$ & $\vdots$ & \\
15 & 69.06630 & 85.54400 & 67.52480 & 34.00630 & 36.63510 & 0.86479 & 0.78692 & 0.55758 & 0.10264 & 0.54632 \\
16 & 53.47800 & 68.64690 & 64.48020 & 77.25230 & 50.95170 & 0.26049 & 0.18986 & 0.40238 & 1.00000 & 1.00000 \\
17 & 57.01570 & 63.27550 & 76.20390 & 39.51250 & 35.74010 & 0.39763 & 0.00006 & 1.00000 & 0.21690 & 0.51796 \\
18 & 61.69230 & 74.66730 & 60.04080 & 35.74660 & 21.33940 & 0.57893 & 0.40259 & 0.17608 & 0.13876 & 0.06162 \\
\hline
\end{tabular}

Step 3: Calculate the grey relational coefficient,

$$
\gamma_{i j}=\frac{\min \left\{\left|1-\eta_{i j}^{*}\right|\right\}+\xi \max \left\{\left|1-\eta_{i j}^{*}\right|\right\}}{\left|1-\eta_{i j}^{*}\right|-\xi \max \left\{\left|1-\eta_{i j}^{*}\right|\right\}}, \quad \forall i, j,
$$

where $\zeta$ is the distinguishing coefficient, which defined in the range $[0,1]$ and it is commonly set 0.5 . Table 8 displays the values of the deviations and grey relational coefficients of each quality response for all experiments.

Step 4: Generate the grey relational grade, $\bar{\gamma}$, as follows:

$$
\bar{\gamma}_{i}=\sum_{j=1}^{5} \gamma_{i j}, \quad \forall i
$$

Table 9 summarizes the values of the grey relational grade for all experiments. Utilizing these values, the grey relation grade mean values are calculated and then displayed in Table 10, where the optimal combination of factor settings is identified as $x_{12}, x_{22}, x_{32}$, and $x_{42}$. While the combination of factor settings at initial factor settings is $x_{13}$, $x_{21}, x_{33}$, and $x_{42}$. The sum of grey grades at initial levels was calculated and found to be 1.9871 . The anticipated improvement in the mean grey grade by using the combination of optimal factor settings is calculated and found to be 0.1729 .

Table 8. Calculated values of the deviations and grey relational coefficients.

\begin{tabular}{cllllllllll}
\hline Exp. $i$ & $\Delta_{i 1}{ }^{*}$ & $\Delta_{i 2}$ & $\Delta_{i 3}$ & $\Delta_{i 4}$ & $\Delta_{i 5}$ & $\gamma_{i 1}$ & $\gamma_{i 2}$ & $\gamma_{i 3}$ & $\gamma_{i 4}$ & $\gamma_{i 5}$ \\
\hline 1 & 0.23300 & 0.76273 & 0.19968 & 0.99672 & 0.66967 & 0.68212 & 0.39597 & 0.71461 & 0.33406 & 0.42747 \\
2 & 0.42147 & 0.00000 & 0.62923 & 0.79070 & 0.22794 & 0.54261 & 1.00000 & 0.44278 & 0.38739 & 0.68687
\end{tabular}




\begin{tabular}{ccccccccccc}
3 & 0.00000 & 0.73604 & 0.69951 & 0.93864 & 0.29801 & 1.00000 & 0.40452 & 0.41684 & 0.34755 & 0.62656 \\
4 & 0.23205 & 0.59768 & 0.97986 & 0.86124 & 0.52408 & 0.68301 & 0.45550 & 0.33787 & 0.36731 & 0.48824 \\
5 & 0.50575 & 0.21277 & 0.94340 & 0.96418 & 0.48717 & 0.49714 & 0.70149 & 0.34640 & 0.34149 & 0.50650 \\
$\vdots$ & $\vdots$ & $\vdots$ & $\vdots$ & $\vdots$ & $\vdots$ & $\vdots$ & $\vdots$ & $\vdots$ & $\vdots$ & $\vdots$ \\
15 & 0.13521 & 0.21308 & 0.44242 & 0.89736 & 0.45368 & 0.78714 & 0.70119 & 0.53055 & 0.35782 & 0.52429 \\
16 & 0.73951 & 0.81014 & 0.59762 & 0.00000 & 0.00000 & 0.40338 & 0.38164 & 0.45553 & 1.00000 & 1.00000 \\
17 & 0.60237 & 0.99994 & 0.00000 & 0.78310 & 0.48204 & 0.45357 & 0.33335 & 1.00000 & 0.38968 & 0.50914 \\
18 & 0.42107 & 0.59741 & 0.82392 & 0.86124 & 0.93838 & 0.54284 & 0.45562 & 0.37767 & 0.36731 & 0.34761 \\
\hline
\end{tabular}

$$
* \Delta_{i}=\left|1-\eta^{*} i j\right| .
$$

Table 9. The grey relational grade.

\begin{tabular}{cccc}
\hline Exp. $i$ & $\bar{\gamma}_{i}$ & Exp. $i$ & $\bar{\gamma}_{i}$ \\
\hline 1 & 0.49205 & 10 & 0.39935 \\
2 & 0.50568 & 11 & 0.39703 \\
3 & 0.46365 & 12 & 0.55984 \\
4 & 0.39781 & 13 & 0.49762 \\
5 & 0.39813 & 14 & 0.53371 \\
6 & 0.60959 & 15 & 0.47088 \\
7 & 0.48335 & 16 & 0.81851 \\
8 & 0.49306 & 17 & 0.63294 \\
9 & 0.51539 & 18 & 0.36420 \\
\hline
\end{tabular}

Table 10. Grey relation grade mean values.

\begin{tabular}{|c|c|c|c|c|}
\hline & & *Factor & & \\
\hline Level & $x_{1}$ & $x_{2}$ & $x_{3}$ & $x_{4}$ \\
\hline level 1 & 0.4696 & $\underline{0.5148}$ & 0.4844 & 0.48 \\
\hline level 2 & 0.4846 & 0.4934 & 0.4681 & $\underline{0.541}$ \\
\hline level 3 & $\underline{0.5512}$ & 0.4973 & $\underline{0.553}$ & 0.4845 \\
\hline$\Sigma$ optimal & \multicolumn{4}{|c|}{2.16} \\
\hline$\Sigma$ initial & \multicolumn{4}{|c|}{1.9871} \\
\hline Improvement & \multicolumn{4}{|c|}{0.1729} \\
\hline
\end{tabular}

* Initial factor and optimal levels are bolded and underscored, respectively.

\section{Results}

Table 11 displays the anticipated improvements in the five quality responses. It is found that, by setting the factors at optimal setting identified using the grey relational analysis, the anticipated improvements $(\mathrm{dB})$ in the cap's height, inner diameter, outer diameter, angle, and plastic weight are calculated and found to be 1.06, -18.11, 1.94, 22.22, and 2.67, respectively. Accordingly, the process factors are suggested to be set as follows: temperature of the cooling system $\left(x_{1}\right)$ at 4 degrees, production rate $\left(x_{2}\right)$ of 1900 piece/minute, extruder speed $\left(x_{3}\right)$ at $35 \mathrm{rpm}$, and temperature of water $\left(x_{4}\right)$ of $3 \mathrm{C}^{\circ}$. Such improvements will result in significant savings in production and quality losses. 
Table 11. The anticipated improvements in quality characteristics using grey grade analysis.

\begin{tabular}{|c|c|c|c|c|c|c|c|c|c|c|c|c|}
\hline \multirow[b]{2}{*}{ *Factor } & \multicolumn{4}{|c|}{ Height } & \multicolumn{4}{|c|}{ Inner diameter } & \multicolumn{4}{|c|}{ Outer diameter } \\
\hline & $x_{1}$ & $x_{2}$ & $x_{3}$ & $x_{4}$ & $x_{1}$ & $x_{2}$ & $x_{3}$ & $x_{4}$ & $x_{1}$ & $x_{2}$ & $x_{3}$ & $x_{4}$ \\
\hline level 1 & 59.89 & $\underline{60.80}$ & 59.03 & 55.54 & 75.51 & 71.11 & 73.72 & 74.46 & 64.36 & 63.74 & 65.43 & 65.43 \\
\hline level 2 & 60.27 & 56.86 & 57.80 & $\underline{60.21}$ & 76.52 & 81.25 & 76.20 & $\underline{78.26}$ & 63.81 & 65.53 & 60.25 & $\underline{61.67}$ \\
\hline level 3 & $\underline{55.93}$ & 58.43 & $\underline{59.26}$ & 60.34 & $\underline{71.32}$ & 70.98 & 73.43 & 70.62 & $\underline{62.65}$ & 61.55 & $\underline{65.14}$ & 63.73 \\
\hline$\Sigma$ optimal & \multicolumn{4}{|c|}{236.2} & \multicolumn{4}{|c|}{294.12} & \multicolumn{3}{|c|}{253.2} & \\
\hline$\Sigma$ initial & \multicolumn{4}{|c|}{235.14} & \multicolumn{4}{|c|}{312.23} & \multicolumn{4}{|c|}{251.26} \\
\hline Improvement & \multicolumn{4}{|c|}{1.06} & \multicolumn{4}{|c|}{-18.11} & \multicolumn{3}{|c|}{1.94} & \\
\hline
\end{tabular}

\begin{tabular}{|c|c|c|c|c|c|c|c|c|}
\hline \multirow[b]{2}{*}{ *Factor } & \multicolumn{4}{|c|}{ Angle (dB) } & \multicolumn{4}{|c|}{ Plastic weight (dB) } \\
\hline & $x_{1}$ & $x_{2}$ & $x_{3}$ & $x_{4}$ & $x_{1}$ & $x_{2}$ & $x_{3}$ & $x_{4}$ \\
\hline level 1 & 37.24 & $\underline{42.66}$ & 34.97 & 36.83 & 31.84 & $\underline{37.09}$ & 34.97 & 31.26 \\
\hline level 2 & 37.36 & 39.65 & 38.57 & $\underline{49.84}$ & 37.44 & 35.36 & 38.27 & $\underline{40.56}$ \\
\hline level 3 & $\underline{47.04}$ & 39.34 & $\underline{48.1}$ & 34.96 & $\underline{39.74}$ & 37.01 & $\underline{36.91}$ & 37.66 \\
\hline$\Sigma$ optimal & & \multicolumn{2}{|c|}{187.64} & \multicolumn{5}{|c|}{154.3} \\
\hline$\Sigma$ initial & & \multicolumn{2}{|c|}{165.42} & \multicolumn{5}{|c|}{151.63} \\
\hline Improvement & & \multicolumn{2}{|c|}{22.22} & \multicolumn{5}{|c|}{2.67} \\
\hline
\end{tabular}

*Note: Initial factor and optimal levels are identified by a bold type and underscore, respectively.

\section{Conclusions}

In this research, the grey relational analysis is employed to optimize caps' manufacturing process for multiple quality characteristics; height, inner diameter, outer diameter, angle, and plastic weight. Four process factors are studied utilizing the Taguchi's orthogonal $\mathrm{L}_{18}$ array. Optimization results showed that the optimal setting of temperature of the cooling system, production rate, and extruder speed. At these settings, the anticipated improvements (dB) in the cap's height, inner diameter, outer diameter, angle, and plastic weight are estimated 1.06, $-18.11,1.94,22.22$, and 2.67 , respectively. The results of this research provide valuable assistance to production engineers on how to enhance the capability of cap's process and improve its quality.

\section{References}

Al-Refaie A. (2014a). Applying process analytical technology framework to optimize multiple responses in waste water treatment process. Journal of Zhejiang, University SCIENCE A, 15(5), 374-384.

Al-Refaie, A. (2010). A Grey-DEA approach for solving the multi-response problem in Taguchi Method. Journal of Engineering Manufacture, 224, 147-158.

Al-Refaie, A. (2012). Optimizing performance with multiple characteristics s using cross-evaluation and aggressive formulation in data envelopment analysis. IIE Transactions, 44, 262-276.

Al-Refaie, A. (2014b). A proposed satisfaction model to optimize process performance with multiple quality responses in the Taguchi method. Journal of Engineering Manufacture, 228, 291-301.

Al-Refaie, A. (2014c). Optimizing performance of low-voltage cables' process with three quality responses using fuzzy goal programming. HKIE Transactions, 21, 1-21.

Al-Refaie, A. (2015). Optimizing multiple quality responses in the Taguchi method using fuzzy goal programming modeling and applications. International Journal of Intelligent Systems, 30, 651-675.

Al-Refaie, A. (2017). Optimal performance of plastic pipes' extrusion process using Min-Max model in fuzzy goal programming. Journal of Process Mechanical Engineering, 231(4), 888-898.

Al-Refaie, A., Chen, T., \& Al-Athamneh, R. (2016). Fuzzy neural network approach to optimizing process performance by using multiple responses. Journal of Ambient Intelligence and Humanized Computing, 7 , $801-816$. 
Al-Refaie, A., Wu, T., \& Li, M. (2009). Data envelopment analysis approaches for solving the multi characteristics problem in the Taguchi method. Artificial Intelligence for Engineering Design, Analysis and Manufacturing, 23, 159-173.

Chakravorty, R., Gauri, S.K., Chakraborty, S. (2012). Optimization of correlated responses of EDM process. Materials and Manufacturing Processes. 27, 337-347.

Deng, J. (1982). Control problems of grey systems. Systems and Control Letters, 1, 288-294.

Deng, J. L. (1989), Introduction to Grey System Theory, Journal of Grey System, 1(1), 1-24.

Fung, C. P. (2003). Manufacturing process optimization for wear property of fiber-reinforced polybutylene terephthalate composites with grey relational analysis. Wear, 254, 298-306.

Huang, J. T., \& Liao, Y. S. (2003). Optimization of machining parameters of Wire-EDM bases on grey relation and statistical analysis. International Journal of Production Research, 41, 1707-1720.

Jiang, B. C., Tasi, S. L., \& Wang, C. C. (2002). Machine vision-based grey relational theory applied to IC marking inspection. IEEE Transactions on Semiconductor Manufacturing, 15, 531-539.

Kacal, A., \& Yildırım, F. (2013). Application of grey relational analysis in high-speed machining of hardened AISI D6 steel. Proceedings of the Institution of Mechanical Engineers, Part C: Journal of Mechanical Engineering Science, 227(7), 1566-1576.

Kuo, Y., Yang, T., \& Huang, G. W. (2008). The use of grey relational analysis in solving multiple attribute decisionmaking problems. Computers \& Industrial Engineering, 55, 80-93.

Lin, C. L., Lin, J. L., \& Ko, T. C. (2002). Optimization of the EDM process based on the orthogonal array with fuzzy logic and grey relation analysis method. International Journal of Advanced Manufacturing Technology, 19, 271-277.

Pan, L. K., Wang, C. C., Wei, S. L., \& Sher, H. F. (2007). Optimizing multiple quality characteristics via Taguchi method-based grey analysis. Journal of Materials Processing Technology, 182, 107-116

Phadke, M. S. (1989). Quality Engineering Using Robust Design. Prentice Hall, Englewood Cliffs: New Jersey.

Somashekhar, K. P., Mathew, J., \& Ramachandran, N. (2011). Multi-objective optimization of micro wire electric discharge machining parameters using grey relational analysis with Taguchi method. Journal of Mechanical Engineering Science, 225(7), 1742-1753.

Taguchi, G. (1995). Quality engineering (Taguchi methods) for the development of electronic circuit technology. IEEE Transactions on Reliability, 44, 225-229.

Tosun, N. (2006). Determination of optimum parameters for multi-performance characteristics in drilling by using grey relational analysis. International Journal of Advanced Manufacturing Technology, 28, 450-455.

Tsao, C. C. (2009). Grey-Taguchi method to optimize the milling parameters of aluminum alloy. International Journal of Advanced Manufacturing Technology, 40(1-2), 41-48.

Yuvaraj, N., \& Pradeep Kumar, M. (2015). Multiresponse optimization of abrasive water jet cutting process parameters using TOPSIS approach. Materials and Manufacturing Processes, 30, 882-889.

\section{Copyrights}

Copyright for this article is retained by the author(s), with first publication rights granted to the journal.

This is an open-access article distributed under the terms and conditions of the Creative Commons Attribution license (http://creativecommons.org/licenses/by/4.0/). 